\title{
Observation of juvenile idiopathic arthritis in children with MEVF gene mutations in Armenia Khloyan Gayane*1,2, RK Saurenmann ${ }^{1}$, Amaryan Gayane ${ }^{1}$ and Karibian Alan ${ }^{1}$
}

Address: ${ }^{1}$ Arabkir Joint Medical Centre, Institute of Child and Adolescent Health, Yerevan, Armenia and ${ }^{2}$ Centre of Medical Genetics and Primary Health Care, Yerevan, Armenia

* Corresponding author

\author{
from I5th Paediatric Rheumatology European Society (PreS) Congress \\ London, UK. 14-17 September 2008 \\ Published: 15 September 2008 \\ Pediatric Rheumatology 2008, 6(SuppI I):P89 doi:10.1 I86/I546-0096-6-SI-P89
}

This abstract is available from: http://www.ped-rheum.com/content/6/SI/P89

(c) 2008 Gayane et al; licensee BioMed Central Ltd.

\section{Background}

The prevalence of Familial Mediterranean fever (FMF) in Armenian people is very high. Acute recurrent or chronic arthritis are possible manifestations of FMF and differentiation from juvenile idiopathic arthritis (JIA) is important.

\section{Aim}

To study the correlation of MEFV mutations with disease susceptibility in patients with JIA

\section{Methods}

Retrospective chart review of all patients with JIA for MEFV mutations and JIA characteristics.

\section{Results}

MEFV analysis was available for 44/69 patients, 7/8 with systemic onset(So) JIA and 37/61 with other types of JIA. MEFV mutations were found in 27/44 patients tested (61\%). 3/7 patients (43\%) with SoJIA had MEFV mutations, all heterozygous. Of the $24 / 37$ patients $(65 \%)$ with other forms of JIA had confirmed MEFV mutations and 12/24 had typical episodes of FMF. With colchicine in addition to standard JIA treatment FMF episodes resolved but they continue to have refractory arthritis. Of the 12 patients without typical FMF episodes 10 had only arthritis and 2 had rare episodes of thoracic pain in addition to the arthritis. In 9/12 patients ( 10 with arthritis only and 2 with thoracic pain) a heterozygous MEFV mutation was found, in 1 patient (8\%) homozygous M694V and 2
(17\%) had compound heterozygous M694V/M680I mutations.

\section{Conclusion}

In our Armenian JIA patients 61\% had MEFV mutations, more than expected. In a population with a high prevalence of FMF MEFV mutations should be tested in children with JIA even in the absence of typical FMF symptoms as chronic arthritis may be the only symptom of FMF. 